\title{
GEOTECNOLOGIAS NO ENSINO BÁSICO: UM ESTUDO DE CASO JUNTO AOS PROFESSORES DA REDE PÚBLICA DE ENSINO DO RIO DE JANEIRO
}

\section{Geotechnologies in basic education: a case study with teachers of public schools in Rio de Janeiro}

\author{
Iomara Barros Sousa \\ Mestranda do Programa de Pós-Graduação de Geografia da UERJ \\ contatoiomara@gmail.com
}

Angelica Carvalho Di Maio

dimaio@vm.uff.br

Artigo recebido em 14/12/2012 e aceito para publicação em 20/01/2013

RESUMO: O objetivo deste trabalho foi investigar a visão dos professores de Geografia sobre o uso das geotecnologias notadamente o Sensoriamento Remoto e Sistema de Informação Geográfica (SIG) como material de apoio ao ensino de Geografia. Utilizou-se, para observação e levantamento de dados e opiniões sobre a utilização das geotecnologias, o curso de formação continuada, para professores da rede pública, denominado "Geoaula: novas tecnologias nas aulas de Geografia do ensino básico", vinculado ao projeto GEOIDEA (Geotecnologia como instrumento da inclusão digital e educação ambiental). Os resultados indicaram que os professores consideram as geotecnologias importantes instrumentos para suas práticas pedagógicas, especialmente com aplicações relacionadas à dinâmica do espaço geográfico.

Palavras-chave: Geotecnologias no ensino; Sensoriamento Remoto e Geografia; Sistema de Informação Geográfica na educação.

ABSTRACT: The objective of this study was to investigate the views of Geography teachers about the use of geotechnologies as tools to support geography teaching, in particular the use of remote sensing and geographic information system (GIS). A training course for the public educational system teachers, called "Geoaula: new technologies in Geography lessons for basic education", was used in the investigation to do the survey about teachers opinions and to observe how they lead to geotechnologies. This course is linked to the project GEOIDEA (Geotechnology as an instrument of environmental education and digital inclusion). The results indicated that teachers consider geotechnologies as important tools in their teaching practices, especially with applications related to the dynamics of geographic space.

Keywords: Geotechnologies in education; Remote Sensing and Geography; Geographic Information System (GIS) in education. 


\section{INTRODUÇÃO}

O aperfeiçoamento das tecnologias de comunicação e informação tem gerado significativas mudanças na sociedade, facilitando a vida das pessoas e possibilitando novas formas de aquisição de conhecimento e, principalmente potencializando ainda mais a capacidade comunicacional inerente ao ser humano, conforme afirmado por Penteado (1998). Para Di Maio (2004), as práticas pedagógicas no ensino de Geografia precisam trabalhar com as tecnologias que permeiam o cotidiano dos alunos aproximando o aluno de seu espaço de estudo, a partir de representações e imagens do presente com informações atualizadas, até mesmo em tempo real, e com possibilidades de comparação com o passado. Há ainda meios para se inferir sobre o futuro de determinados recortes espaciais, permitindo aos alunos identificar, relacionar e compreender a inter-relação entre fenômenos naturais e sócioeconômicos que ocorrem na superfície terrestre, desde a escala local até a global.

A proposta de integrar a ciência espacial na educação geográfica vai ao encontro dos Parâmetros Curriculares Nacionais do Ensino Fundamental para a Geografia, quando é enfatizado que o aluno deve ser capaz de utilizar diferentes fontes de informações e recursos tecnológicos para adquirir e construir conhecimentos geográficos. Assim, a Cartografia Escolar deve estar relacionada ao ensino de Geografia com objetivo de atender as necessidades dos estudantes em seu cotidiano. Pois possibilita o mesmo a perceber o ambiente em que vive, relevando as características físicas, econômicas, sociais e humanas do ambiente e as suas transformações (ALVES, 2011).

A aplicação integrada das novas tecnologias na ciência cartográfica, notadamente o Sensoriamento Remoto, que permite a obtenção de informações sobre a identificação e características de diferentes alvos no nosso planeta por meio de sensores aéreos ou orbitais, e os Sistemas de Informações Geográficas (SIG), que auxiliam nas análises espaciais,a partir da integração de dados de diversas fontes e da criação de bancos de dados georreferenciados, redefine a cartografia contemporânea. Sendo esta, vista agora também, como a disciplina que representa a informação geográfica utilizando a geoinformação na forma gráfica, analógica e digital (TAYLOR, 1991). Para Taylor (1991), a exigência para o entendimento da complexidade da sociedade moderna é grande e há poucas disciplinas como a cartografia que respondem a essa demanda, uma vez que, segundo o autor, "o mapa é um meio de navegação, de fundamental importância em um mar turbulento de dados e informações de uma larga gama de tópicos".

Dessa forma, baseado na potencial contribuição das geotecnologias no ensino, para obtenção de informações sobre o espaço geográfico em diferentes escalas espaciais e temporais e na análise da dinâmica espacial, o presente trabalho analisou, por meio do curso de extensão para professores "GeoAula II: novas tecnologias nas aulas de Geografia do ensino básico"1, vinculado ao projeto GEOIDEA $^{2}$ (Geotecnologia como instrumento da inclusão digital e educação ambiental), a visão dos professores do ensino básico, de escolas públicas do estado do Rio de Janeiro, sobre o uso das geotecnologias nas aulas de Geografia.

O Projeto GEOAULA visou a capacitação dos docentes para o uso do material instrucional GEOIDEA, que aborda o uso das tecnologias de sensoriamento remoto e SIG no ensino fundamental e médio, a partir da proposição de atividades no SIG EduSPRING. O projeto GEOIDEA (DI MAIO et al.; 2009) buscou desenvolver e aplicar metodologia voltada para a inclusão digital de alunos do ensino básico $\left(6^{\circ}\right.$ ao $9^{\circ}$ ano do ensino fundamental e ensino médio), através do uso de Sistema de Informação Geográfica nas aulas de Geografia, abordando o tema transversal Meio Ambiente.

\section{O PROFESSOR NA SOCIEDADE DA INFORMAÇÃO (DIGITAL) E O ENSINO DE GEOGRAFIA}

A educação é o elemento chave para inserção das pessoas na sociedade do conhecimento. Segundo Filmus (2003, p. 
12), "a função da escola não se resume apenas ao ensino de conteúdos específicos, ela deve também se empenhar na tarefa de ensinar a aprender por meio das mais diversas fontes de comunicação $e$ informação em razão da sua importância na transmissão/construção de conhecimentos, valores, conceitos e cultura". Takahashi (2011, p. 3) afirma que a "educação escolar é elemento chave na construção da sociedade baseada na informação, no conhecimento e no aprendizado". A incorporação das novas tecnologias de comunicação e informação nas instituições escolares redefine o papel do professor na sociedade do conhecimento, que se amplia muito, conforme afirmado por Kenski (2001). A autora relata que "novas qualificações para estes professores são exigidas, mas ao mesmo tempo, novas oportunidades de ensino se apresentam" ( $p$. $70)$.

Para Kenski (1998), o educador em muito se beneficiará ao compreender esse novo mundo tecnológico, uma vez que as tecnologias no ensino podem funcionar como ferramentas auxiliares em sua prática pedagógica. Para a autora, a inclusão do ambiente digital em situações de aprendizagem dentro dos espaços escolares não se traduz na substituição do professor; ao contrário, o papel deste profissional permanece primordial em sala de aula ao promover a interação e a integração entre os alunos. Cada vez mais, o processo de ensino-aprendizagem na sociedade da informação exige do professor não apenas conhecimentos referentes aos seus conteúdos disciplinares, mas também habilidades para criar e manusear metodologias adequadas e criativas, utilizando a tecnologia disponível como aliada das práticas pedagógicas.

Hasse (1999) afirma que a escola de hoje precisa corresponder aos estímulos do progresso tecnológico e científico e ser estimulante e atrativa para a juventude, e enfatiza que, "não podemos pensar em escolas pobres para pobres. Temos que pensar em uma escola que possibilite as duas coisas: de um lado, a apropriação de conhecimentos e habilidades que independem do computador, e, de outro, devemos pensar uma escola que possibilite a apropriação e o uso deste e de outros instrumentos que sejam significativos $\mathrm{e}$ importantes para a vida do ser humano" (LUCKESI, 1988, p.41, apud HASSE, 1999, p.128).

Desta forma, é importante que os docentes participem da formação continuada, uma vez que a formação do professor exige novos olhares sobre os currículos de ensino, e assim desenvolvam nos seus alunos habilidades e competências para atuarem como cidadãos críticos $\mathrm{e}$ futuros profissionais em uma sociedade da informação, onde o conhecimento sobre o espaço é também fundamental no processo de formação da cidadania.

\section{O PROJETO GEOIDEA}

O projeto GEOIDEA ${ }^{2}$ consistiu no desenvolvimento e aplicação de metodologia voltada para a inclusão digital de alunos do ensino básico ( $3^{\circ}$ ciclo do Ensino Fundamental e Ensino Médio), através do uso de Sistema de Informação Geográfica, nas aulas de Geografia. Este trabalho gerou, em ambiente digital, material didático com temas relacionados à Geografia, Cartografia, tecnologia espacial, Meio Ambiente (biomas, bacias hidrográficas, unidades de conservação da natureza). As atividades propostas são realizadas por meio do Sistema de Informação Geográfica EduSPRING versão especializada do aplicativo SPRING 5.0/INPE (CÂMARA et al., 1996), que foi simplificado para as aplicações nas atividades escolares (Figura 1). 


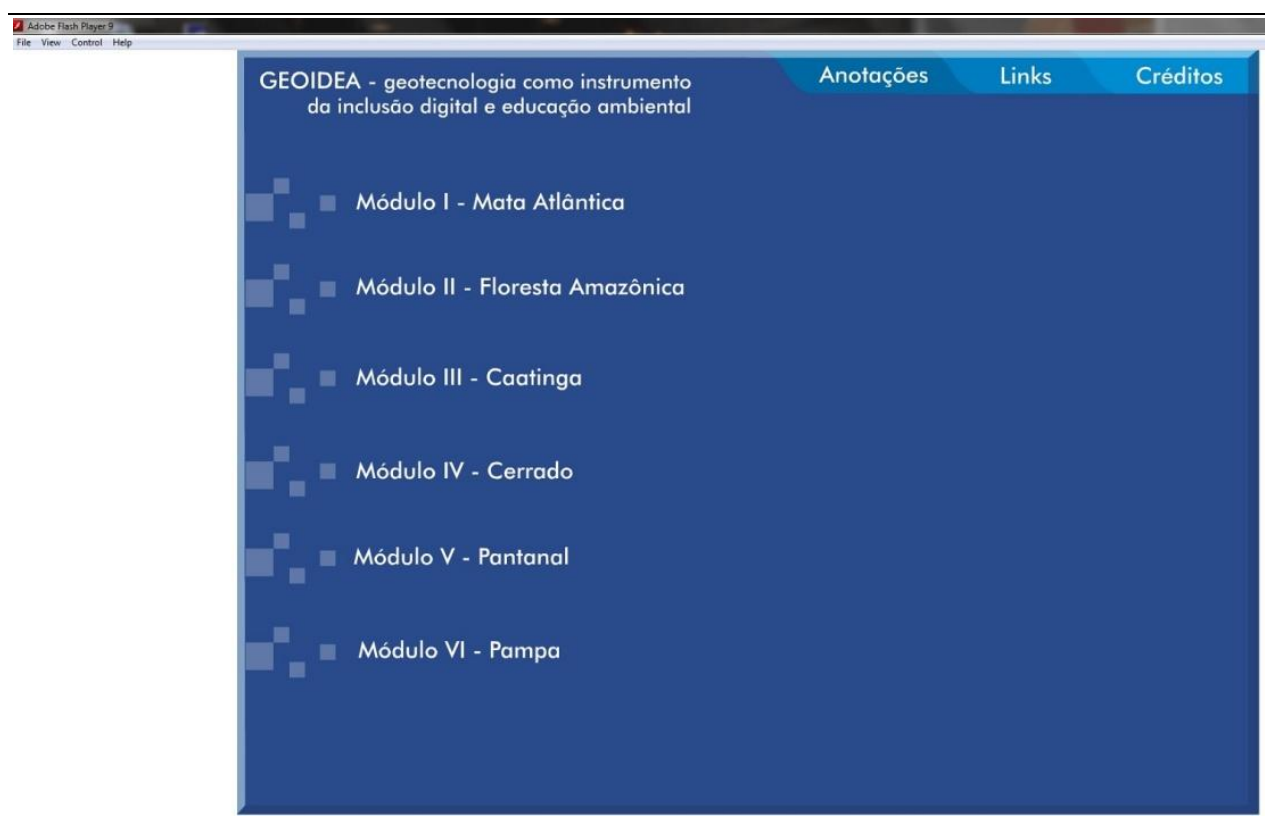

Figura 1. Exemplo da estrutura do CD-ROM GEOIDEA

Como resultado, foi gerado em ambiente flash um material didático, disponível em CD-ROM. Este material contem o software EduSPRING, o banco de dados sobre os biomas brasileiros (mapas, imagens de satélites e dados vetoriais); além do caderno de exercícios, curiosidades, sugestões de sites para pesquisas e um Guia eletrônico para o professor (Figura 2).

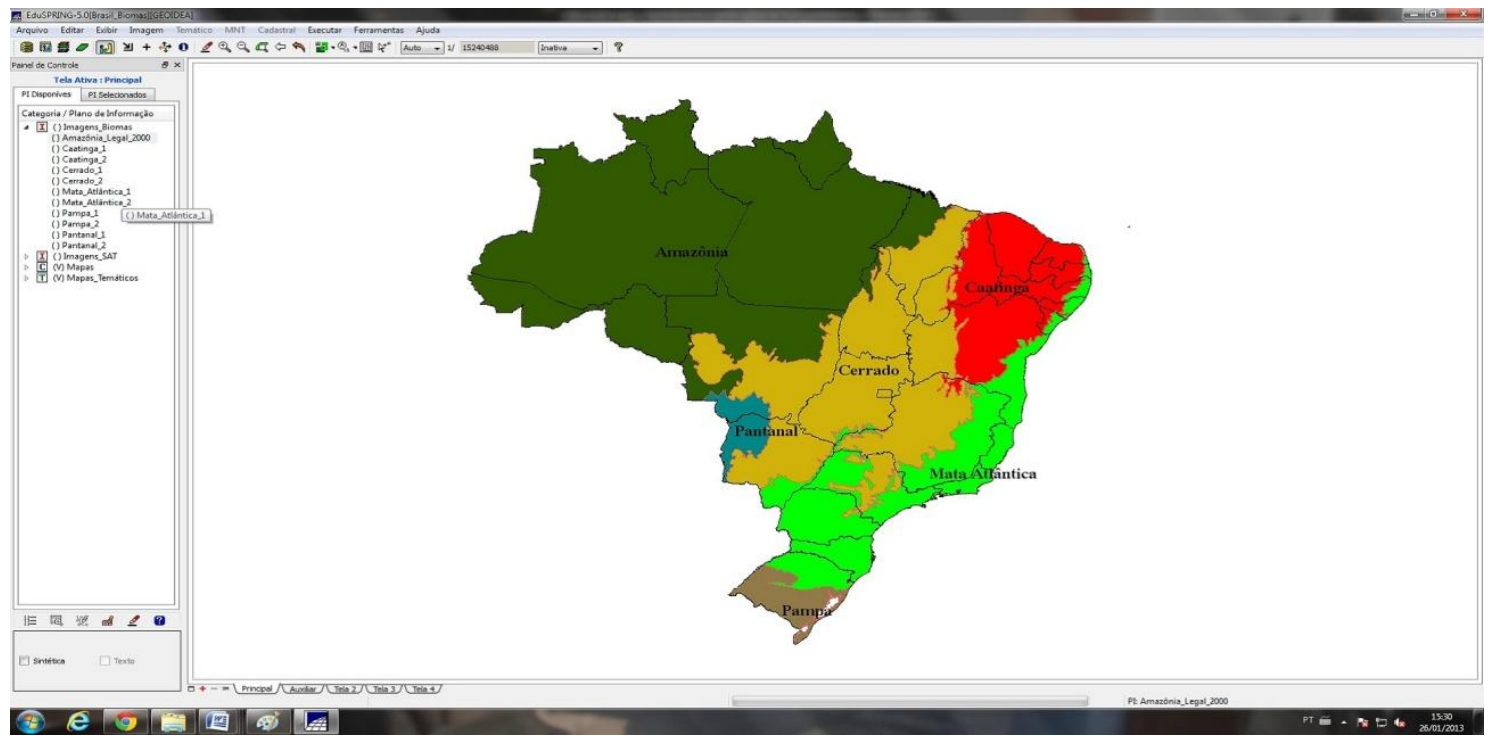

Figura 2. Atividade desenvolvida no EduSPRING

Foram utilizados recursos de Geotecnologias (Sensoriamento Remoto, Sistema de Informação Geográfica e Sistema de Posicionamento Global - GPS), e da Cartografia Digital, em atividades que estavam em consonância com os Parâmetros Curriculares Nacionais (PCN) da Geografia e do tema transversal Meio Ambiente. As atividades foram organizadas em módulos. Cada módulo correspondeu a um bioma: Módulo I - Bioma Mata Atlântica; Módulo II - Bioma Floresta Amazônica; Módulo III - Bioma Caatinga; Módulo IV - Bioma Cerrado; Módulo V Bioma Pantanal e Módulo VI - Bioma Pampa.

As atividades propostas foram agrupadas da seguinte forma de acordo com os objetivos (DI MAIO et al., 2009): 
a) Cartografia: Desenvolver atividades envolvendo conceito da cartografia como coordenadas geográficas, orientação e escala. O estudante localiza os biomas dentro do território brasileiro por regiões e estados. $\mathrm{O}$ aluno se aproxima do lugar.

b) Geral: Identificar as características desses biomas utilizando os mapas temáticos de clima e hidrografia. Realizar cálculos de área, distância e extensão. Identificar os Parques Nacionais encontrados nos biomas e Terras indígenas. O estudante faz correlações.

c) Específico: Desenvolver atividades com uso de sensoriamento remoto por meio de imagens de satélite. Identificar o uso do solo, ocupação humana, desmatamento, áreas agrícolas, áreas urbanas, as características climáticas, hidrográficas. Realizar cálculos de área e distâncias. O aluno faz correlações e encontra explicações para a ocupação do espaço.

\section{O PROJETO DE EXTENSÃO GEOAULA}

O projeto GeoAula teve como objetivo disseminar novas tecnologias no ensino de Geografia a partir da capacitação de professores no uso de tecnologias como imagens orbitais, Internet e sistemas de informações geográficas. Este projeto realizou curso de capacitação para professores do ensino básico no uso das geotecnologias em sala de aula, como meio de revitalização das aulas de Geografia, na rede pública de ensino do estado do Rio de Janeiro.

O Curso teve uma carga de 40 horas, e foi ministrado no Laboratório de informática do Colégio Estadual Nilo Peçanha, em São Gonçalo, RJ. Dezessete professores das redes municipais e da rede estadual do Rio de Janeiro participaram. O curso contemplou: Atualização de conteúdos (Elementos da Cartografia Básica, Sensoriamento remoto e Sistemas de informação Geográfica e uso do Sistema de posicionamento global - GPS) e Aulas práticas no Laboratório (Figura 3).

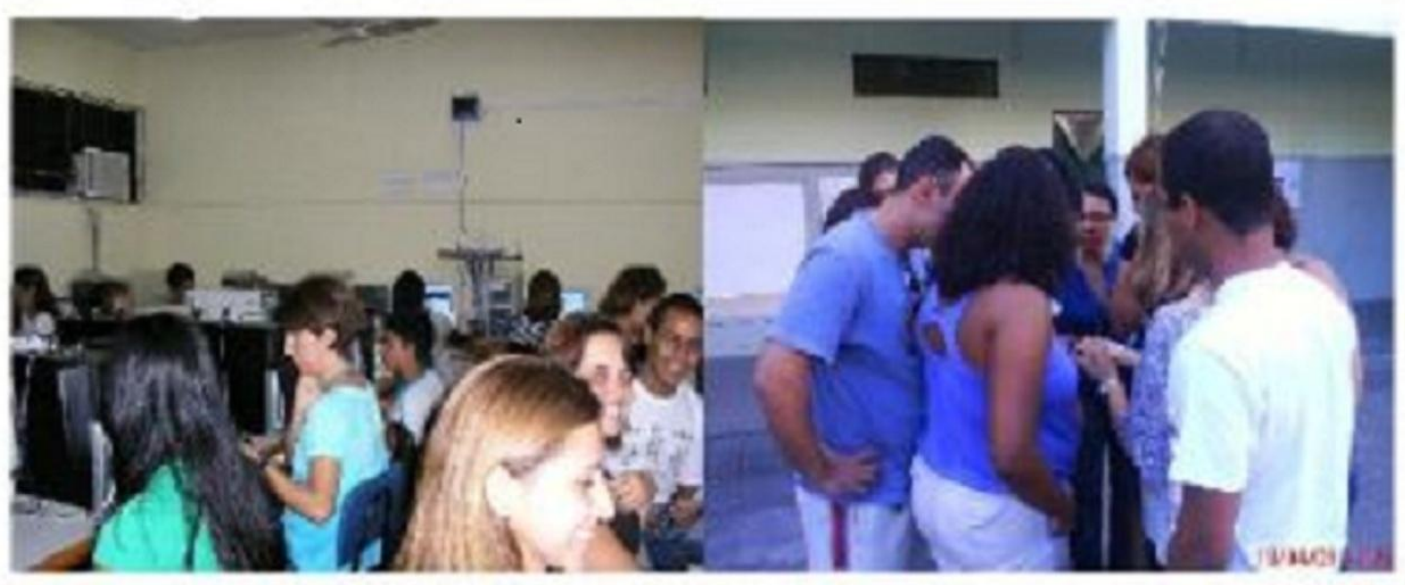

Figura 3. Realização de atividades práticas do GEOIDEA/EduSPRING no laboratório de informática e no pátio da escola com o GPS.

\section{COLETA DE INFORMAÇÕES COM BASE EM QUESTIONÁRIOS}

$\begin{array}{lcr}\text { Buscou-se } & \text { investigar } & \text { o } \\ \text { posicionamento dos } & \text { professores de } \\ \text { Geografia da Educação Básica sobre o uso } \\ \text { das geotecnologias referentes ao } \\ \text { Sensoriamento Remoto e ao Sistema de }\end{array}$

Informação Geográfica como um recurso didático nas suas práticas pedagógicas; para tanto, os dados foram coletados por meio da aplicação três questionários distintos, com perguntas abertas e fechadas, feitas aos professores participantes do curso "de extensão "GeoAula II: novas tecnologias nas aulas de Geografia do ensino básico". A 
aplicação dos questionários consistiu em diferentes propostas; assim, o primeiro questionário procurou investigar as concepções e conhecimentos que os professores possuiam em relação as tecnologias de Sensoriamento Remoto e SIG, anterior a realização do curso, e suas aplicabilidades no ensino de Geografia; ao final do curso, foram aplicados mais dois questionários. $\mathrm{O}$ segundo procurou investigar de que forma o curso contribuiu para o entendimento sobre Sensoriamento Remoto e SIG e a sua importância como material potencial para aprimorar $\mathrm{o}$ conhecimento do aluno na dinâmica espacial; e, por último, o terceiro questionário consistiu em fazer um diagnóstico do GEOIDEA, constatando os aspectos positivos e as possíveis aplicabilidades nas aulas de Geografia, bem como os aspectos negativos que permitiram reformular o material didático em meio digital.

Quanto ao perfil dos professores, constatou-se que a grande maioria dos docentes possuía mais de 10 anos de exercício de magistério com licenciatura plena como formação acadêmica.

\section{RESULTADOS}

O primeiro questionário teve como objetivo fazer um levantamento do perfil dos professores participantes do curso em relação as suas práticas didáticopedagógicas frente às possibilidades do uso das novas tecnologias da informação e comunicação (TCIs), especialmente o uso do computador e da internet como ferramentas de apoio ao ensino e aprendizagem de Geografia; Além disso, buscou-se analisar a concepção desses docentes a respeito da introdução do Sensoriamento Remoto e do SIG para promover o entendimento da dinâmica espacial nas suas inter-relações com elementos naturais e sócio-econômicos.

Verificou-se que os professores possuíam conhecimentos básicos de informática, mais especificamente do sistema operacional Windows, através do pacote Office (Word, Power Point e Excel), o que facilita o uso dos computadores no espaço escolar. Entretanto, professores possuem conhecimentos sobre o sistema operacional Linux instalado nos computadores das escolas públicas. A maioria dos professores já utiliza o computador aliado à Internet para realizar alguma atividade pedagógica, como o acesso a sites, os mais citados foram: Greenpeace, IBGE e Observatório Nacional.

Constatou-se também que os professores, já possuíam algum conhecimento prévio sobre Sensoriamento Remoto, antes da realização do curso, pois $71 \%$ das respostas, ou seja, 12 professores responderam que utilizam as imagens do Google Earth como recurso didático e, apenas $29 \%$ das respostas, ou seja, 5 professores disseram não usar esse recurso no ensino.

Os educadores mencionaram que a tecnologia de Sensoriamento Remoto no ensino de Geografia possibilitava trabalhar, ao mesmo tempo, a dinâmica do espaço vivido dos alunos e o espaço global; acrescentaram ainda que o uso dessa tecnologia em suas práticas pedagógicas permitia aos alunos obterem informações atualizadas sobre a dinâmica espacial. Isso cria condições para aproximar os conhecimentos da ciência em relação ao cotidiano dos alunos o que, muitas vezes, desperta e estimula um maior interesse pelas aulas de Geografia, ou conforme relatado por Carvalho (2006) quando disse que
"o aluno pode ver esse espaço geográfico atualizado, observando-o, comparando e identificando suas transformações, o que causa uma grande impressão nos alunos e, a partir dos dados coletados por meio destas observações, pode-se criar a necessidade de se questionar, analisar e refletir sobre como a realidade se apresenta" (p.34).

Por último, os professores demonstraram concordar fortemente que o papel do professor de Geografia se altera e, muito na sociedade digital, o que requer destes profissionais atualizações constantes de seus conhecimentos e práticas pedagógicas 
Ao término do curso, foram aplicados mais dois questionários.

O segundo questionário teve como objetivo verificar como os professores avaliaram o GEOIDEA (em relação aos bancos de dados, SIG EduSPRING, exercícios, sugestões de pesquisa) como instrumento de apoio à disciplina de Geografia do ensino básico.

Os professores consideraram $\mathrm{o}$ GEOIDEA um material que poderia auxiliar os alunos, especialmente na compreensão de temas como Cartografia (localização), Interpretação de imagens e Biomas Brasileiros, através das tecnologias de Sensoriamento Remoto e SIG. Ainda, consideraram que os itens "curiosidades" e "sites para interação" no GEOIDEA possibilitariam o desenvolvimento de um ensino mais dinâmico e motivador, na medida em que o professor poderia trabalhar com as tecnologias da contemporaneidade da maioria dos alunos.

Além disso, foi observado que os professores estão dispostos a utilizar os recursos tecnológicos na sala de aula, como
SIG, fotografias aéreas e imagens de satélites no $3^{\circ}$ e $4^{\circ}$ ciclos do Ensino Fundamental II e no Ensino Médio; todavia, existem dificuldades por parte dos professores para interpretar cartas e trabalhar com as imagens de satélites. Neste sentido, ressalta-se a importância das secretarias municipais e estaduais de educação na oferta de cursos de formação continuada, possibilitando aos docentes utilizar os recursos tecnológicos em suas aulas e, com isso desenvolvendo de uma prática didática sintonizada com os anseios dos alunos e com informações atualizadas.

Os conteúdos didáticos ou instrumentos utilizados no estudo da superfície terrestre abordados no GEOIDEA, tais como: escala, sistema de coordenadas geográficas, orientação, interpretação de plantas, cartas e mapas, interpretação do relevo nas cartas (curvas de nível), imagens de satélites, sistema de informação geográfica (Eduspring), Geografia/biomas e Geografia/percepção espacial foram avaliados pelos professores conforme mostra a Tabela 1.

Tabela 1. Grau de dificuldade dos professores participantes do curso

\begin{tabular}{|l|l|l|l|}
\hline \multirow{2}{*}{ Conteúdos e instrumentos } & \multicolumn{3}{c|}{ Avaliação dos professores } \\
\cline { 2 - 5 } & Alto (0-3) & Médio (46) & Baixo (7-9) \\
\hline 1- Escala & 6 & 5 & 2 \\
\hline 2- Sistema de Coordenadas Geográficas & 3 & 6 & 3 \\
\hline 3- Orientaçäo & 2 & 6 & 4 \\
\hline 4 Interpretação de plantas, cartas e mapas & 6 & 6 & 1 \\
\hline $\begin{array}{l}\text { 5- Interpretaçăo do relevo nas cartas (curvas de } \\
\text { nivel) }\end{array}$ & 8 & 3 & 2 \\
\hline 6- Imagens de satélites & & & \\
\hline $\begin{array}{l}\text { 7- Sistema de Informação Geográfica } \\
\text { (EduSPRıNG) }\end{array}$ & 8 & 1 & 2 \\
\hline 8- Geografia (biomas) & 9 & 3 & 1 \\
\hline 9- Geografia (percepçä̊ espacial) & 1 & 6 & 5 \\
\hline
\end{tabular}

Os professores avaliaram os conteúdos e instrumentos do GEOIDEA; as respostas foram agrupadas e, por sua vez classificadas quanto ao nível de dificuldade alto, médio e baixo, em uma escala que variava de zero a nove. Quanto mais próximo de zero, menor o nível de dificuldade em relação aplicação do conteúdo por meio do GEOIDEA nas aulas de Geografia. Por outro lado, quanto mais próximo de nove, maior foi o nível de dificuldade do conteúdo ou instrumento de auxílio ao ensino de Geografia, classificado assim pelos professores, para ser trabalhado em suas aulas, como por exemplo, o uso de imagens de satélites, que foi considerado difícil (8). NaTabela 1, percebe-se que a maioria dos professores, por meio da escala de avaliação do GEOIDEA, considerou que os conteúdos ou instrumentos utilizados no 
estudo da superfície terrestre abordados no GEOIDEA possuem um nível difícil e médio para aplicação no ensino básico. Mais detalhes das questões respondidas pelos professores podem ser encontradas em Silva (2009).

O terceiro questionário aplicado teve como objetivo analisar o posicionamento dos professores, após participarem do curso, sobre o uso específico de imagens de satélites (sensoriamento remoto) e do EduSPRING
(SIG) e suas possíveis aplicações na Geografia Escolar.

Os professores classificaram o curso como muito proveitoso. Além disso, avaliaram positivamente a utilização do EduSPRING como um SIG educacional. A respeito do nível de ensino, todos os professores utilizariam o GEOIDEA como instrumento educativo em meio digital no $3^{\circ}$ e $4^{\circ}$ ciclos do Ensino Fundamental $\left(6^{\circ}\right.$ ao $9^{\circ}$ ano), e $86 \%$, ou seja, 12 professores o usariam também no Ensino Médio (Figura 4).

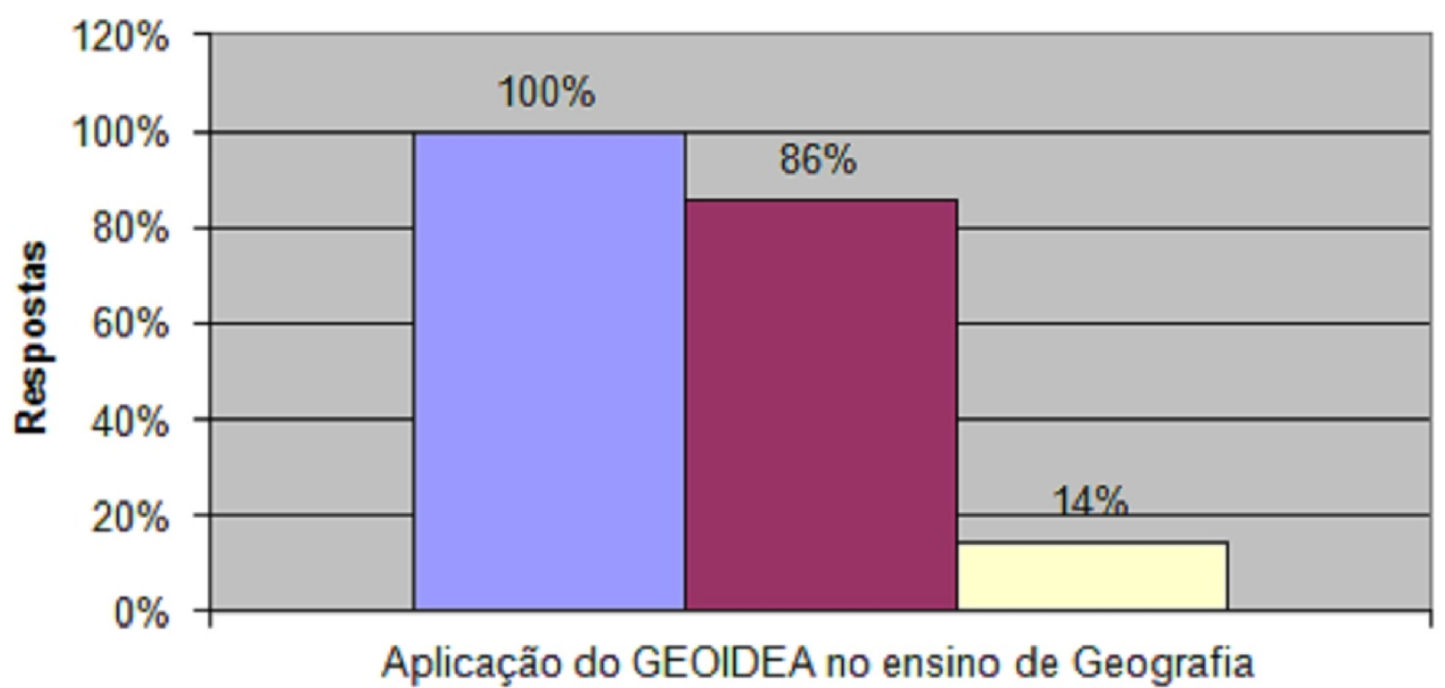

Figura 4. Percentual dos professores que utilizariam do GEOIDEA no ensino fundamental e médio.

Os professores acreditam que o SIG associado ao sensoriamento remoto e à cartografia digital possa ser usado para trabalhar a realidade geográfica do lugar onde os alunos vivem e, ainda fazer análises concomitantemente de diferentes escalas espaciais e temporais. $\mathrm{O}$ que vai ao encontro da posição de Carvalho (2006), que diz que a introdução dessas tecnologias no ensino de Geografia possibilita estudar o espaço geográfico, pois propicia $o$ desenvolvimento de um processo desencadeador de questões a serem respondidas, tanto em relação à geografia física como também questões relativas à geografia humana, ou seja, as relações dentro da sociedade e de como esta se apropria do espaço e reproduz seus conflitos.

O recurso didático trabalhado pelos professores, as geotecnologias, possibilita a resolução de exercícios sobre coordenadas geográficas, permite criar exercícios sobre a localização de lugares a partir de coordenadas e a coleta de coordenadas a partir da definição de lugares; por último, permite a elaboração de novos mapas a partir de combinações de planos de informação. Por exemplo, os professores enxergaram a possibilidade de poder trabalhar o processo de urbanização, indicadores sociais e problemas ambientais; aspectos demográficos; segregação sócioespacial e os padrões irregulares de ocupação, atuando assim conforme, expressado por Julião (1999), como Geocidadãos.

\section{CONSIDERAÇÕES FINAIS}

É preciso que sejam oferecidos cursos de formação continuada aos professores abordando o uso de geotecnologias aplicadas ao ensino, pois conforme foi mostrado pelas respostas dos questionários, os professores consideram 
valioso aplicar essas tecnologias ao ensino de Geografia, no entanto, os docentes ainda possuem dificuldades ao usar dados do Sensoriamento Remoto e manipular um SIG. Hoje existem vários SIGs disponíveis e gratuitos, assim como as imagens orbitais e até fotografias aéreas, o que propicia a inserção da ciência e tecnologia na sala de aula.

As geotecnologias possibilitam aos professores trabalhar com dados mais atualizados sobre o espaço geográfico, inclusive com o espaço próximo do aluno, uma cidade, um bairro ou mesmo um quarteirão, suprindo assim, a carência de mapas e representações espaciais que facilitam a visualização e interpretação do espaço geográfico em constante transformação.

Este trabalho teve como principal proposta analisar a visão dos professores sobre o uso das geotecnologias referentes ao Sensoriamento Remoto e ao SIG no Ensino Fundamental II e Ensino Médio da rede pública de ensino. Após as análises dos três questionários, observou-se que $\mathrm{o}$ computador aliado a Internet tem sido utilizado no espaço escolar como um dos instrumentos de ensino pelos professores de Geografia. A maioria desses profissionais concorda ser positivo o uso das geotecnologias em sua prática didáticopedagógica; muitos desses profissionais já utilizam o Google Earth para trabalhar conteúdos de Geografia, o que proporciona um ensino dinâmico e revitalizador e, principalmente sem custos diretos, no caso do uso de imagens e aplicativos gratuitos. No entanto, ainda há outros fatores, desestimulantes para os professores, como a realidade dos laboratórios de informática das escolas públicas. A maioria dos computadores não possuem uma boa capacidade de processamento e armazenamento de informações geográficas e a quantidade de alunos por turma, em média 35 alunos, associado ao reduzido número de computadores nos laboratórios de informática, dificulta um trabalho inovador. Por essa razão, é preciso que cada professor, ao fazer uso do computador em sua prática de ensino, possa refletir sobre a realidade tecnológica da escola onde leciona, a fim de que realize atividades educativas condizentes com ela, mas que não deixe de realizá-las. Afinal, segundo os estudos de Perrenoud (2000), os progressos tecnológicos tais como o uso de aplicativos não deve ser dispensado das salas de aulas, tendo em vista as suas contribuições para o processo de ensino e aprendizagem. O autor reforça que a escola não pode ignorar o que se passa no mundo, e deve incentivar o uso das tecnologias em favor de operações mentais, aprendizagens e construção de competências.

De acordo com Fagundes et al. (2001), devemos entender que.

"... estamos juntos para estudar, para aprender, para desenhar melhor as transformações, para implementar estas transformações nos currículos, para retomar as mais ricas experiências do passado - as práticas curriculares mais criativas - e, por meio delas, experimentar as melhores aplicações das novas tecnologias" (p.10).

São os desafios para os sistemas de ensino, entretanto, para, os indivíduos menos favorecidos representam a possibilidade do acesso à informação e ao direito à participação e ao crescimento (MARANHÃO, 2002).

Por essas razões, os professores solicitaram novos cursos de capacitação, o que demonstrou que, apesar das inúmeras dificuldades enfrentadas por eles em seus cotidianos, como por exemplo, a falta de tempo e recursos financeiros, eles estão dispostos a repensar sobre futuras mudanças em suas práticas pedagógicas, incorporando as geotecnologias, como facilitadoras no processo de compreensão das transformações espaciais.

\section{NOTAS}

\footnotetext{
1 Projeto apoiado pela Pró-Reitoria de Extensão da Universidade Federal Fluminense, realizado em 2009.

${ }^{2}$ Projeto apoiado pela FAPERJ $\left(\mathrm{n}^{\mathrm{o}}\right.$. E26/110.200/2007) no âmbito do Programa de Melhoria do Ensino Público no Estado do Rio de Janeiro.
} 


\section{REFERÊNCIAS BIBLIOGRÁFICAS}

ALVES, Taíse dos Santos. A utilização do aplicativo Google Maps no processo de ensino-aprendizagem da cartografia: uma experiência na escola pública. In: Anais XV Simpósio Brasileiro de Sensoriamento Remoto - SBSR, Curitiba, PR, Brasil, INPE p.3408, 2011.

CÂMARA Gilberto, SOUZA Ricardo C.M., FREITAS Ubirajara M., GARRIDO Juan \& MITSUO II, Fernando. SPRING: Integrating remote sensing and GIS by object-oriented data modeling. Computers \& Graphics, vol. 20, n³, pp. 395-403, 1996.

CARVALHO, Vânia Maria Salomon Guaycuru. Sensoriamento Remoto no ensino básico da geografia: definindo novas estratégias. 284 p. Tese (Doutorado em Geografia). Centro de Ciências Matemáticas e da Natureza, Universidade Federal do Rio de Janeiro. 2006.

DI MAIO, Angelica Carvalho. Geotecnologias Digitais no Ensino Médio: avaliação prática de seu potencial. 189 p. Tese (Doutorado em Geografia). Instituto de Geociências e Ciências Exatas, Universidade Estadual Paulista Júlio de Mesquita Filho, 2004.

DI MAIO, Angelica Carvalho. FRANCISCO, Cristiane. LEVY, Carlos. PINTO, Cláudia. NUNES, Eusébio. CARVALHO, Marcus. DORNELAS, Thaís. GEOIDEA - Geotecnologia como instrumento da inclusão digital e educação ambiental. Anais. In: Simpósio Brasileiro de Sensoriamento Remoto, 14, 2009, Natal. São José dos Campos: INPE, p. 2397-2404, 2009.

FAGUNDES Léa da Cruz; SATO, Luciane Sayuri; MAÇADA, Débora Laurino . Aprendizes do Futuro: as Inovações Começam! Coleção Informática para a Mudança na Educação. Disponível em: $<$ http://www.proinfo.gov.br/biblioteca/publi cacoes/livro03.pdf>. Acesso em: 04 ago. 2001.
FILMUS, Daniel. Breve reflexões sobre a escola do futuro e apresentação da experiência da experiência "aulas na rede" da cidade de Buenos Aires. In: TEDESCO, Juan. Educação e Novas Tecnologias: esperanças ou incerteza? São Paulo: Cortez, p. 123-136, 2003.

Hasse, Simone Hedwig A Informática na Educação: Mito ou Realidade. In: Lombardi, José Carlos (org). Pesquisa em Educação, História, Filosofia e Temas Transversais. Campinas, ed. Autores Associados: HISTEDBR, Unc, 1999.

JULIÃO, Rui Pedro. Geografia, Informação e Sociedade. Geoinova, Lisboa, p. 95-108, jun 1999.

KENSKI, Vânia Maria. A Profissão do Professor em um mundo em Rede: exigências de hoje, tendências e construção do amanhã: professores hoje é o futuro. Tecnologia Educacional, São Paulo, n. 26, p.65-69, out 1998.

KENSKI, Vânia Maria. O Papel do Professor na Sociedade Digital. In CASTRO, Amélia Domingues. CARVALHO, Anna Maria Pessoa (org.). Ensinar a Ensinar: Didática para a Escola Fundamental e Média. São Paulo: Pioneira Thomson Learning, p. 95-106, 2001.

MARANHÃO, Magno A. Telecomunidade e Exclusão Digital. Jornal Gazeta do Povo. Curitiba, PR. Disponível em: $<$ http://www.magnomaranhao.pro.br/artigos 2002.html>, Acesso em 05 de fevereiro de 2002.

PENTEADO, Heloisa Dupas. Pedagogia da comunicação: sujeitos comunicantes. In: PENTEADO, H.D. (Org.) Pedagogia da comunicação: teorias e práticas. São Paulo: Cortez, 1998. p. 13-22.

PERRENOUND, $\quad$ Philippe. 10 Competências para ensinar.1. ed. Porto Alegre: Artmed, 2000.

SILVA, Dantas Barros Iomara. Geotecnologias como recurso didático no ensino básico-um estudo de caso junto aos 
professores da rede pública. São Gonçalo, 2009. 65 p. Monografia (Especialização em Educação Básica/Ensino de Geografia). Centro de Educação e Humanidades, Faculdade de Formação de Professores -São Gonçalo, Universidade do Estado do Rio de Janeiro.

TAKAHASHI, T. (Org.) Sociedade da Informação no Brasil - Livro Verde. Brasília, set. 2000. Disponível em: <http://livroaberto.ibict.br/bitstream/1/434/ 1/ livroverde.pdf. $>$ Acesso em: 23.abr.2011.

Taylor,D.R.F. A conceptual Basis for cartography/New Directions for The Information Era, Cartographica, vol. 28, No 4, 1991, pp 1-8. 